\title{
CRYOGENIC TREATMENT OF Cr-V DIE STEEL IN LIQUID HELIUM - EFFECT ON MECHANICAL PROPERTIES
}

\author{
${ }^{1}$ Peter JURČI, ${ }^{1}$ Jana PTAČINOVÁ, ${ }^{2} I v o$ DLOUHÝ \\ ${ }^{1}$ Faculty of Materials Sciences and Technology in Trnava, Slovak Technical University of Technology \\ in Bratislava, Slovak Republic, EU, p.jurci@seznam.cz \\ 2Institute of Physics of Materials, CEITEC-IPM, Czech Academy of Sciences, Brno, Czech Republic, EU, \\ idlouhy@ipm.cz
}

https://doi.org/10.37904/metal.2019.707

\begin{abstract}
The microstructure and mechanical properties of Vanadis 6 ledeburitic tool steel, which was subjected to subzero treatment in liquid helium, has been examined with reference of the same material after conventional room temperature quenching. It has been found that the sub-zero treatment considerably reduces the amount of retained austenite, and increases the number and population density of carbides. As a result of SZT, the hardness, the flexural strength and the fracture toughness of the material are improved, except minor cases.
\end{abstract}

Keywords: Vanadis 6 steel, sub-zero treatment, liquid helium, microstructure, mechanical properties

\section{INTRODUCTION}

The benefits of sub-zero treatments (SZTs) on the wear performance [1,2], dimensional stability [3,4] and hardness [1,3] of tools made of $\mathrm{Cr}$ ledeburitic steels have been known for more than one century. However, the choice of an "optimal" temperature of SZT is still an open issue. In the 1950s it was commonly accepted that temperatures down to approx. $-79^{\circ} \mathrm{C}\left(-120^{\circ} \mathrm{F}\right)$ are sufficient to transform high portion of retained austenite $\left(\gamma_{\mathrm{R}}\right)$ into the martensite, and lower temperatures have no practical effect on the properties of steels. Much later, a temperature of boiling nitrogen $\left(-196^{\circ} \mathrm{C}\right)$ was suggested for treatment. This treatment further increases the performance of tools, as demonstrated upon results of real industrial testing [5].

Mentioned ameliorations are attributed to the following changes in the microstructure of sub-zero treated steels compared to conventionally heat treated ones: reduction of $\gamma_{R}$ amount $[1,6,7]$, acceleration of precipitation rate of nano-sized transient carbides [7,8], formation of great number of small globular carbides during the subzero period $[1,7,9]$, and to the martensite refinement $[6,7]$.

High strength and hardness, and superior wear performance of $\mathrm{Cr}$ and $\mathrm{Cr}-\mathrm{V}$ ledeburitic steels are often connected with their poor toughness. Moreover, the obtained results of toughness/fracture toughness quantification manifest an evident inconsistency. Molinari et al. [10], for instance reported on almost no effect of SZT on toughness of AISI D2 steel while Collins and Dormer [9] and Rhyim et al. [11] recorded considerable reduction of this measure by SZT of the same steel grade. The flexural strength has been employed as an indirect method for evaluation of toughness of Vanadis 6 in our recent studies $[12,13]$. It has been found the SZT at $-196{ }^{\circ} \mathrm{C}$ has only negligible or rather positive impact on the flexural strength of Vanadis 6 steel. Das et al. [1] reported deterioration of the fracture toughness due to application of SZT for the AISI D2 steel while our recent investigations on the Vanadis 6 steel indicated slight deterioration of fracture toughness after SZT at $196{ }^{\circ} \mathrm{C}$ [12], and its general improvement after treatment at $-140^{\circ} \mathrm{C}[13]$.

The boiling temperature of liquid helium $\left(-269^{\circ} \mathrm{C}\right)$ has been suggested by several authors for the treatment $[14,15,16]$, but the achieved results did not meet expectations, due to either too short processing time applied in the case of AISI D2 steel [15] or inappropriately chosen material for the treatment [16]. The current conference paper deals with the quantification of flexural strength and fracture toughness of Cr-V ledeburitic 
die steel Vanadis 6 when subjected to the SZT in liquid helium. The same steel after conventional heat treatment is used as a reference.

\section{MATERIAL AND EXPERIMENTAL METHODS}

The experimental material was ledeburitic tool steel Vanadis 6 with a nominal composition (in wt. \%) of $2.1 \mathrm{C}$, $1.0 \mathrm{Si}, 0.4 \mathrm{Mn}, 6.8 \mathrm{Cr}, 1.5 \mathrm{Mo}, 5.4 \mathrm{~V}$, Fe as the balance, delivered in soft-annealed state. Two types of specimens were manufactured - the rod test samples with dimensions of $10 \mathrm{~mm} \times 10 \mathrm{~mm} \times 100 \mathrm{~mm}$ were intended for the flexural strength determination while pre-cracked specimens with dimensions of $10 \mathrm{~mm} \times 10$ $\mathrm{mm} \times 55 \mathrm{~mm}$ were used for the fracture toughness examination.

The specimens were net-shape machined, and heat treated as follows: Conventional heat treatment (CHT) consisted of heating up to the austenitizing temperature of $1050{ }^{\circ} \mathrm{C}$ in a vacuum furnace, hold at that temperature for $30 \mathrm{~min}$, which was followed by nitrogen gas quenching. One half of specimens were instantly subjected to tempering. The second half of specimens was moved to cryogenic system, where they were cooled down at a cooling rate of $1{ }^{\circ} \mathrm{C} / \mathrm{min}$ to the temperature of $-196{ }^{\circ} \mathrm{C}$ and held there for $15 \mathrm{~min}$. After that the samples were moved into Dewar's container filled with liquid He, cooled down to the temperature of -269 ${ }^{\circ} \mathrm{C}$ and held there for $17 \mathrm{~h}$. Subsequently, the material was moved back to the cryogenic system with liquid nitrogen, held there for $15 \mathrm{~min}$, and then warmed up to the room temperature, by a heating rate of $1^{\circ} \mathrm{C} / \mathrm{min}$. Double tempering $(2+2 \mathrm{~h})$ was performed immediately, at temperatures ranging from 170 to $530^{\circ} \mathrm{C}$. However, one set of specimen has been analysed in untempered state.

The specimens for microstructural examinations were prepared by grinding, polishing with 9,3 and $1 \mu \mathrm{m}$ diamond slurry, and etching by using a picral reagent ( $4 \%$ picric acid solution in ethanol). The microstructures as well as the fractured surfaces of broken specimens after testing of mechanical properties have been investigated using the scanning electron microscopy (SEM). A JEOL JSM 7600F device coupled with energydispersive spectroscopy (EDS)-detector Oxford Instruments, has been used. For the determination of population density $\left[1 / \mathrm{mm}^{2}\right]$ of carbides, at least thirty digital micrographs were randomly acquired in order to ensure the statistical reliability associated with these assessments. The mean values and standard deviations have been calculated from the obtained results. The $\gamma_{R}$ amounts were determined by X-ray diffraction (XRD), in accordance with appropriate ASTM standard [17].

For determination of flexural strength and fracture toughness, an Instron 8862 machine was used; the samples were loaded in three-point bending with a roller span of $40 \mathrm{~mm}$ (fracture toughness) or $80 \mathrm{~mm}$ (flexural strength), and a loading rate of $0.1 \mathrm{~mm} / \mathrm{min}$ was applied. Specimen deflection was measured by means of an inductive transducer integrated directly into the loading axis. In total, five samples were tested for each investigated condition. Hardness measurements were completed by the Vickers (HV10) method. Ten measurements were made for the metallographic specimens processed with any combination of heattreatment parameters, and both the mean values and standard deviations were then calculated.

\section{RESULTS AND DISCUSSION}

Figure 1 is a compilation of SEM micrographs acquired from differently heat treated specimens. The steel contains the matrix and carbides. The matrix is formed by the dominant amount of the martensite. The retained austenite is located in-between the martensitic domains, as tiny elongated formations, Figures 1a, c. The material contains three main carbide types, namely eutectic particles (ECs), secondary carbides (SCs), and small globular carbides (SGCs). The amount of the latter ones is significantly enhanced by SZT in liquid helium compare Figure 1a with Figure 1c. Enhanced amount of SGCs in SZT steel is maintained after tempering, compare micrographs in Figure 1b with Figure 1d, even though the number of these particles decreases with tempering, Figure 2. Moreover it is clearly seen that the SGCs are not distributed uniformly in SZT steel but there are some sites with preferential occurrence of these particles, Figure 1c. 


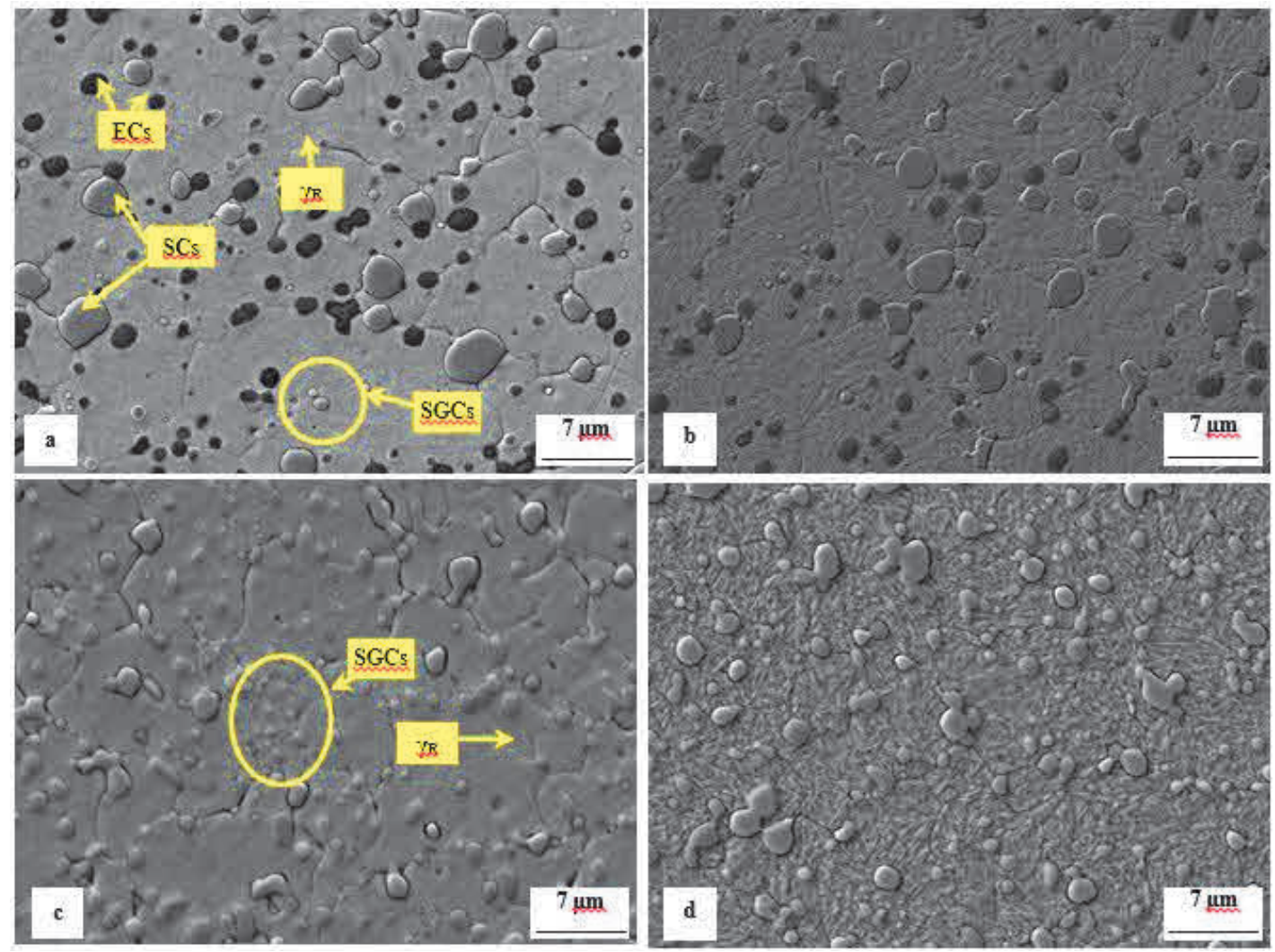

Figure 1 Microstructure of the Vanadis 6 steel after $\mathrm{CHT}(\mathrm{a}), \mathrm{SZT}$ at $-269^{\circ} \mathrm{C}(\mathrm{b}), \mathrm{CHT}$ and tempering at 530 ${ }^{\circ} \mathrm{C}$ (c), SZT at $-269^{\circ} \mathrm{C}$ and subsequent tempering at $530^{\circ} \mathrm{C}$ (d).

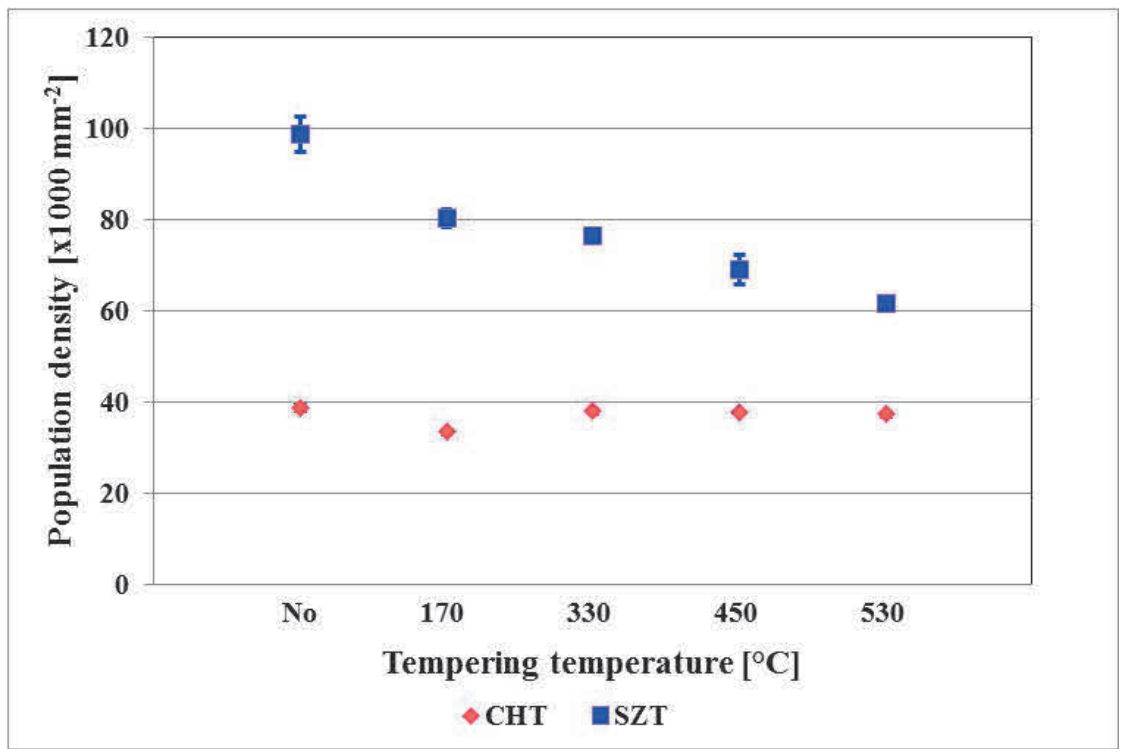

Figure 2 Population density of SGCs in CHT Vanadis 6 steel and in the same steel after SZT at $-269^{\circ} \mathrm{C}$, for differently tempered specimens.

As shown in Table 1 the application of SZT reduces the retained austenite amount more than fivefold. In the case of $\mathrm{CHT}$ the retained austenite is almost constant, up to the tempering temperature of $450{ }^{\circ} \mathrm{C}$, and tempering at $530^{\circ} \mathrm{C}$ removes this phase almost completely from the material. Also, tempering acts in favour 
of the retained austenite decomposition in the case of SZT steel. The $\gamma_{R}$ decomposition is accelerated by the SZT since it is seen that this phase is eliminated from the material after tempering at $450{ }^{\circ} \mathrm{C}$.

Table 1 Retained austenite amounts for differently heat treated steel specimens

\begin{tabular}{|c|c|c|c|c|c|}
\hline $\begin{array}{c}\text { Tempering } \\
\text { temperature }\left({ }^{\circ} \mathrm{C}\right)\end{array}$ & No & $\mathbf{1 7 0}$ & $\mathbf{3 3 0}$ & $\mathbf{4 5 0}$ & $\mathbf{5 3 0}$ \\
\hline $\mathrm{CHT}$ & $20.2 \pm 1.6$ & $20.5 \pm 2.6$ & $20.1 \pm 1.8$ & $19.4 \pm 1.8$ & $2.0 \pm 0.4$ \\
\hline $\mathrm{SZT}$ & 3.7 & 1.9 & 1.7 & b.d.I & b.d.l. \\
\hline
\end{tabular}
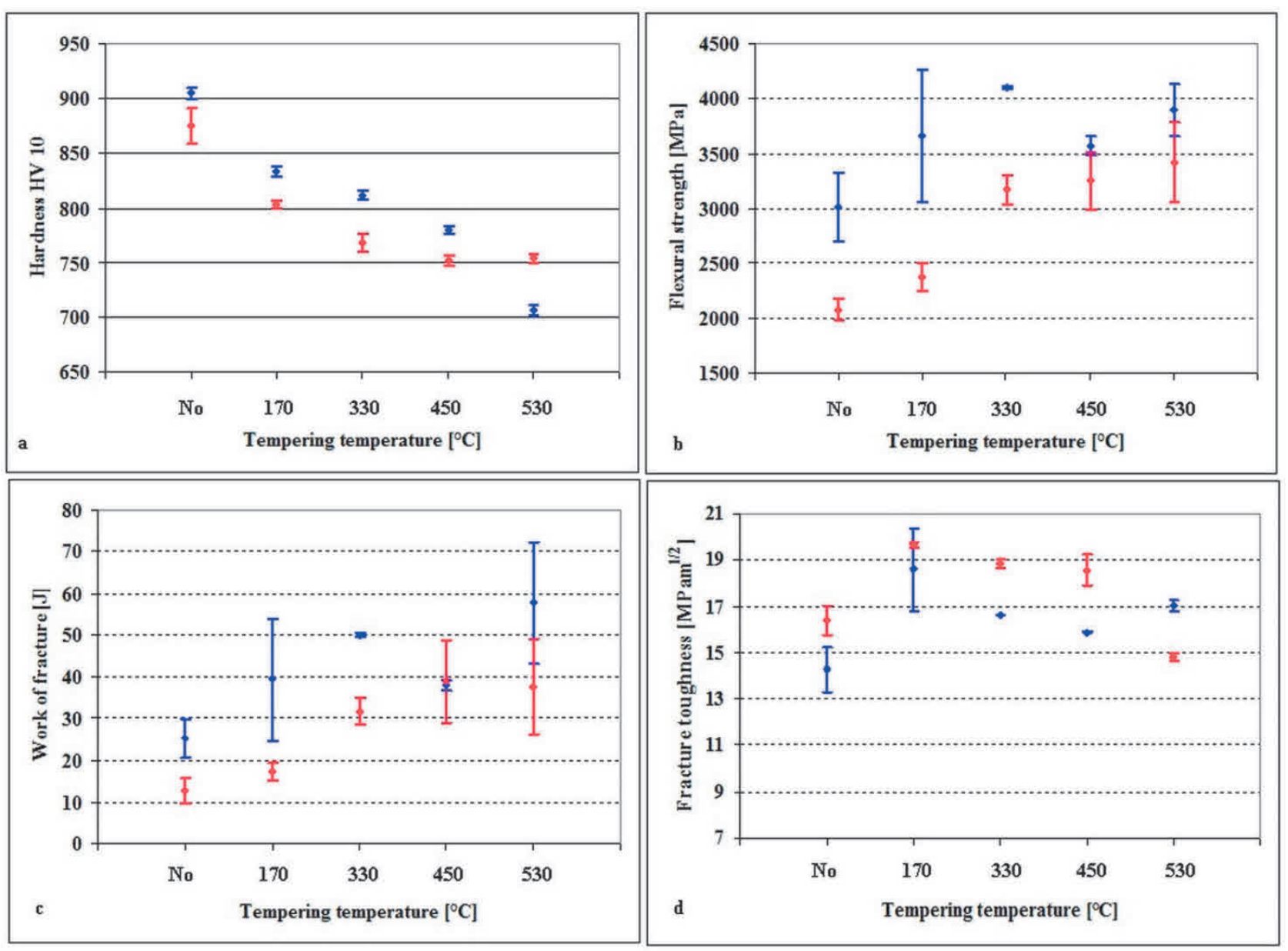

Figure 3 Mechanical properties of differently heat treated specimens made of Vanadis 6 steel, hardness (a), flexural strength (b), work of fracture (c), and fracture toughness (d).

Figure 3 depicts the dependence of the hardness (a), flexural strength (b), work of fracture (c), and fracture toughness (d) on tempering temperature for both the CHT and SZT steel. The hardness of SZT steel is enhanced over the $\mathrm{CHT}$ one, and this tendency is maintained up to the tempering temperature of $450{ }^{\circ} \mathrm{C}$. However, after tempering at $530{ }^{\circ} \mathrm{C}$ the $\mathrm{CHT}$ steel manifest a weak secondary hardness peak while the hardness of SZT material decreases rapidly, and becomes lower as compared with what was obtained by $\mathrm{CHT}$. The flexural strength is improved by the application of SZT over the whole range of tempering treatments used. This is also well reflected in the behaviour of work of fracture. Alternatively, the fracture toughness is slightly deteriorated by the application of SZT, except the case of the tempering at the temperature of secondary hardening, where an opposite tendency has been recorded. 
Figure 4 shows representative fractographs of the fractured $K_{\mathrm{IC}}$ specimens that were $\mathrm{CHT}$ and SZT at $-269{ }^{\circ} \mathrm{C}$, in both untempered state and in the state after tempering at $530{ }^{\circ} \mathrm{C}$. The main difference between the $\mathrm{CHT}$ specimens and the ones after SZT is that the fractured surfaces of CHT samples manifest flat morphology, Figures $\mathbf{4 a}, \mathbf{b}$ (this is much more pronounced in tempered specimen, Figure $\mathbf{4 b}$ ) while the fractured surfaces of SZT material appear rougher, with many small dimples and clearly evident micro-plastic deformation. Mentioned differences are in excellent agreement with recorded $K_{\mathrm{I}}$ values, and also with the microstructural parameters. SZT specimens contain considerably enhanced number and population density of carbides. The carbide/matrix interfaces act more probably as sites for micro-void coalescence mechanism of the fracture propagation, which is associated with micro-plastic deformation of the matrix, Figures $\mathbf{4 c}$, d. Alternatively, CHT steel contains more retained austenite. This is soft and relatively ductile phase, which contributes to higher $K_{\mathrm{IC}}$ values. However, the retained austenite is eliminated from the material almost completely when tempered at $530^{\circ} \mathrm{C}$, and special alloy carbides precipitate from supersaturated solid solutions [7]. This has a strengthening effect on the matrix, which becomes less amenable to deform plastically. As a result, the fracture toughness is very low after this kind of treatment, and the fractured surface appear correspondingly smooth, with clear indications of cleavage crack propagation manner.

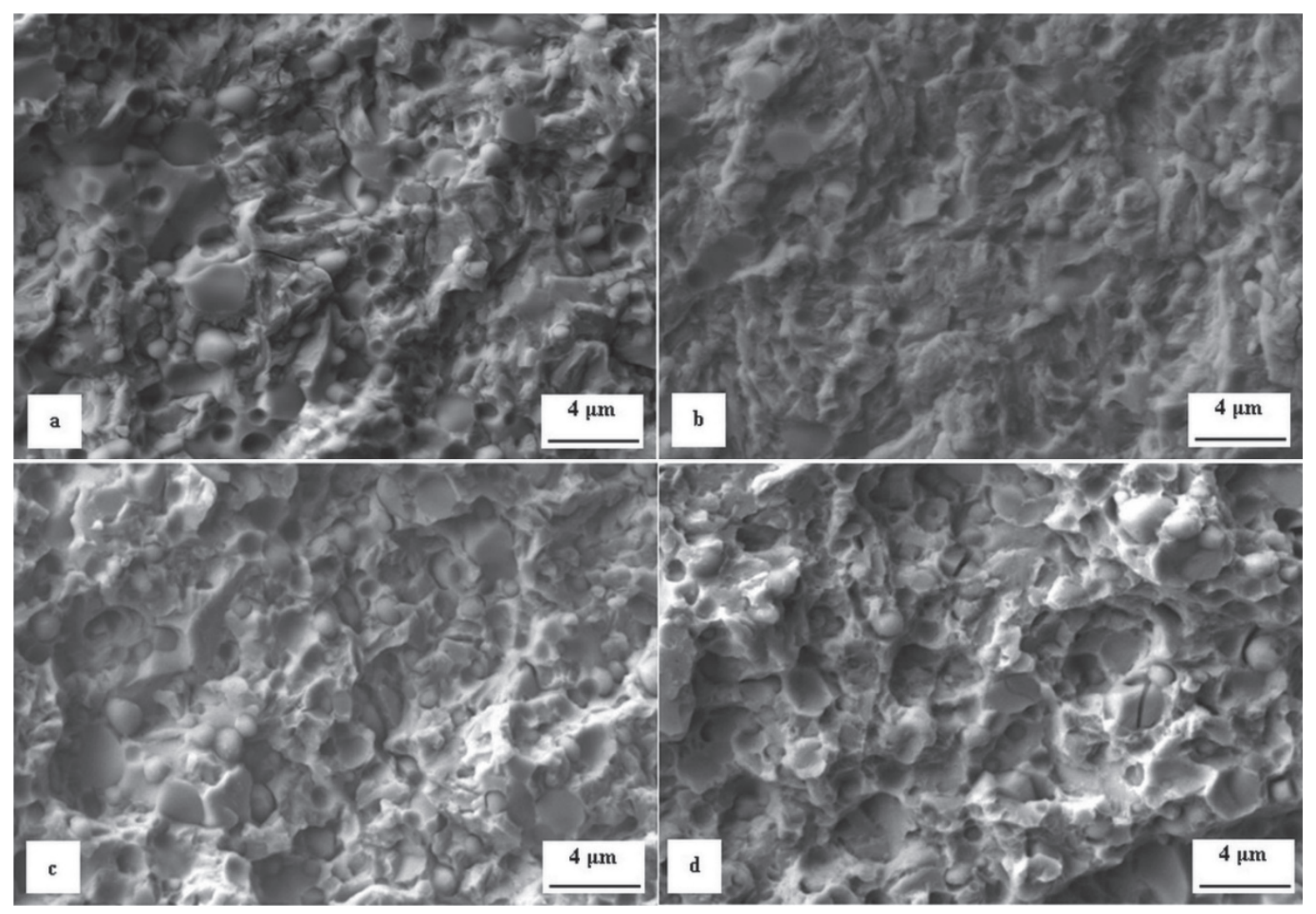

Figure 4 Fractured surfaces of $K_{\mathrm{IC}}$ specimens of the Vanadis 6 steel after $\mathrm{CHT}$ (a), SZT at $-269^{\circ} \mathrm{C}(\mathrm{b}), \mathrm{CHT}$ and tempering at $530^{\circ} \mathrm{C}(\mathrm{c}), \mathrm{SZT}$ at $-269^{\circ} \mathrm{C}$ and subsequent tempering at $530^{\circ} \mathrm{C}(\mathrm{d})$.

\section{CONCLUSION}

The examinations of microstructure and mechanical properties of Vanadis 6 ledeburitic tool steel, which was subjected to sub-zero treatment in liquid helium led to the following main findings:

The retained austenite amount was more than fivefold reduced in comparison with conventionally heat treated steel. Moreover, sub-zero treatment accelerated the retained austenite decomposition in tempering. 
Sub-zero treatment induces formation of considerably enhanced amount of small globular carbides.

The hardness of sub-zero treated steel is enhanced as compared with conventionally treated one at low tempering temperatures but tempering at the secondary hardening temperature evokes rapid hardness decrease of sub-zero treated steel.

The flexural strength of sub-zero treated steel is improved but the effect of this kind of treatment on fracture toughness is ambiguous. In the low temperature tempering range the fracture toughness is rather deteriorated while it is improved after the tempering to the secondary hardening.

\section{ACKNOWLEDGEMENTS}

The authors acknowledge that the paper is a result of experiments performed within project VEGA 1/0264/17. In addition, this publication is the result of the project implementation "Centre for Development and Application of Advanced Diagnostic Methods in Processing of Metallic and NonMetallic Materials - APRODIMET', ITMS: 26220120014, supported by the Research \& Development Operational Programme funded by the ERDF.

\section{REFERENCES}

[1] DAS, D. and RAY, K. K. Structure-property correlation of subzero treated AISI D2 steel. Materials Science and Engineering. 2012. vol. A541, pp. 45 - 60.

[2] THORNTON, R., SLATTER, T. and GHADBEIGI, H. Effects of deep cryogenic treatment on the dry sliding wear performance of ferrous alloys. Wear. 2013. vol. 305, pp. 177 - 191.

[3] BERNS, H. Restaustenit in ledeburitischen Chromstählen und seine Umwandlung durch Kaltumformen, Tiefkühlen und Anlassen. HTM. 1974. vol. 29, pp. 236 - 247.

[4] SURBERG, C.H., STRATTON, P. and LINGENHÖLE, K. The effect of some heat treatment parameters on the dimensional stability of AISI D2. Cryogenics. 2008. vol. 48, pp. 42 - 47.

[5] REITZ, W. and PENDRAY, J. Cryoprocessing of Materials: A Review of Current Status. Materials and Manufacturing Processes. 2001. vol. 16, pp. 829 - 840.

[6] TYSHCHENKO, A.I., THEISEN, W., OPPENKOWSKI, A., SIEBERT, S., RAZUMOV, O.N., SKOBLIK, A.P., SIROSH, V.A., PETROV, J.N. and GAVRILJUK, V.G. Low-temperature martensitic transformation and deep cryogenic treatment of a tool steel. Materials Science and Engineering. 2010. vol. A527, pp. 7027 - 7039.

[7] JURČI, P., DOMÁNKOVÁ, M., HUDÁKOVÁ, M., PTAČINOVÁ, J., PAŠÁK, M. and PALČEK, P. Characterization of microstructure and tempering response of conventionally quenched, short- and long-time sub-zero treated PM Vanadis 6 ledeburitic tool steel. Materials Characterization. 2017. vol. 134, pp. 398 - 415.

[8] LI, S., MIN, N., LI, J., WU, X., LI, Ch. and TANG, L. Experimental verification of segregation of carbon and precipitation of carbides due to deep cryogenic treatment for tool steel by internal friction method. Materials Science and Engineering. 2013. vol. A575, pp. 51 - 60.

[9] COLLINS, D.N. and DORMER, J. Deep Cryogenic Treatment of a D2 Cold-Work Tool Steel. Heat Treatment of Metals. 1997. vol. 24, pp. 71 - 74.

[10] MOLINARI, A., PELLIZZARI, M., GIALANELLA, S., STRAFFELINI, G. and STIASNY, K.H. Effect of deep cryogenic treatment on mechanical properties of tool steels. Journal of Materials Processing Technology. 2001. vol. 118, pp. 350 - 355.

[11] RHYIM, Y.M. HAN, S.H., NA, Y.S. and LEE, J.H. Effect of deep cryogenic treatment on carbide precipitation and mechanical properties of tool steel. Solid State Phenomena. 2006. vol. 118, pp. 9 - 14.

[12] PTAČINOVÁ, J., SEDLICKÁ, V., HUDÁKOVÁ, M., DLOUHÝ, I. and JURČI, P. Microstructure - Toughness relationships in sub-zero treated and tempered Vanadis 6 steel compared to conventional treatment. Materials Science and Engineering. 2017. vol. A702, pp. 241 - 258. 
[13] JURČI, P., ĎURICA, J., DLOUHÝ, I., HORNÍK, J., PLANIETA, R. and KRALOVIČ, D. Application of $-140{ }^{\circ} \mathrm{C}$ subzero treatment for $\mathrm{Cr}-\mathrm{V}$ ledeburitic steel service performance improvement. Metallurgical and Materials Transactions, 2019, https://doi.org/10.1007/s11661-019-05180-6

[14] STRATTON, P.F. Optimising nano-carbide precipitation in tool steels. Materials Science and Engineering. 2007. vol. A449 - 451, pp. 809 - 812.

[15] ZURECKI, Z. Cryogenic Quenching of Steel Revisited. In: Proc. 23 ${ }^{\text {rd }}$ Heat Treating Society Conference. Pittsburgh, PA, USA. 2005. pp. 106 - 114.

[16] STRATTON, P. and GRAF. M. The effect of deep cold induced nano-carbides on the wear of case hardened components. Cryogenics. 2009. vol. 49, pp. 346 - 349.

[17] ASTM E975-13: Standard Practice for X-Ray Determination of Retained Austenite in Steel with Near Random Crystallographic Orientation, ASTM Book of Standards, vol. 3.01, West Conshohocken, PA, USA, 2004. 